\title{
Prevention is the role of governments, not health systems
}

\section{Fiona Godlee editor in chief \\ The BMJ Follow Fiona on Twitter @fgodlee}

We are told that prevention is at the heart of the long term plan for the NHS, published last week (doi:10.1136/bmj.180; doi:10. 1136/bmj.185). This sounds like good news; prevention is, after all, better than cure. But we should be wary of suggestions that it's the role of the NHS to prevent disease. There are many good elements of secondary prevention in the plan, as Rachel Chapman and John Middleton point out this week (doi:10.1136/ bmj.1218), but there are also many other calls on the NHS's limited resources.

What of primary prevention? Unless we invest in this for the long term, any health service will struggle to keep pace with the rising tide of chronic physical and mental illness. Instead, we have austerity and cuts to local authority funding of public health. Proper primary prevention means tackling the social determinants of health and also commercial vested interests. Sadly, although this government talks a good talk, its actions tell a different story.

Take alcohol. As Alison Douglas and Ian Gilmore write (doi:10. 1136/bmj.1190), England's health secretary, Matt Hancock, is happy to acknowledge alcohol as one of the top five causes of premature death in the UK and to fund interventions to help people cut down. But he says he won't consider introducing a minimum unit price, ignoring evidence that this would save many lives and a great deal of money. Cowardice? Hypocrisy?
Or, as Douglas and Gilmore suspect, industry influence? "Why would Hancock take against such a policy now?" they ask. "The alcohol industry was quick to welcome his statement. It would be worrying if the health secretary is listening to the views of those vested interests above those of the health community." Of course, industries lobby governments directly to promote their own interests, but their greatest impact may be more covert. In China, as Susan Greenhalgh reports (doi:10.1136/bmj.k5050), Coca-Cola's funding of an apparently independent think tank has successfully perverted research and government policy by diverting attention away from Coke's disastrous role in the obesity epidemic (doi:10.1136/bmj.14).

Even in the best regulated circles, commercial vested interests will find a way in. NICE works hard to be transparent and free from hidden influence, but patients' groups may be its Achilles' heel. As Kate Mandeville and colleagues report (doi:10.1136/ bmj.k5300; doi:10.1136/bmj.1129), commercial support is common among the patient groups involved in NICE's appraisals of the evidence. Most of this money wasn't declared; and in most cases a declaration wasn't required by NICE.

These are skirmishes in a long and unequal battle. If our governments align themselves with commercial rather than public interests, we cannot win. 